\title{
Optimization and Comparison of ESI and APCI LC-MS/MS Methods: A Case Study of Irgarol 1051, Diuron, and their Degradation Products in Environmental Samples
}

\author{
Niki C. Maragou, Nikolaos S. Thomaidis, Michael A. Koupparis
}

Laboratory of Analytical Chemistry, Department of Chemistry, University of Athens, Panepistimioupolis Zografou, 15771 Athens, Greece

\begin{abstract}
A systematic and detailed optimization strategy for the development of atmospheric pressure ionization (API) LC-MS/MS methods for the determination of Irgarol 1051, Diuron, and their degradation products (M1, DCPMU, DCPU, and DCA) in water, sediment, and mussel is described. Experimental design was applied for the optimization of the ion sources parameters. Comparison of ESI and APCl was performed in positive- and negative-ion mode, and the effect of the mobile phase on ionization was studied for both techniques. Special attention was drawn to the ionization of DCA, which presents particular difficulty in API techniques. Satisfactory ionization of this small molecule is achieved only with ESI positive-ion mode using acetonitrile in the mobile phase; the instrumental detection limit is $0.11 \mathrm{ng} / \mathrm{mL}$. Signal suppression was qualitatively estimated by using purified and non-purified samples. The sample preparation for sediments and mussels is direct and simple, comprising only solvent extraction. Mean recoveries ranged from $71 \%$ to $110 \%$, and the corresponding (\%) RSDs ranged between 4.1 and $14 \%$. The method limits of detection ranged between 0.6 and $3.5 \mathrm{ng} / \mathrm{g}$ for sediment and mussel and from 1.3 to $1.8 \mathrm{ng} / \mathrm{L}$ for sea water. The method was applied to sea water, marine sediment, and mussels, which were obtained from marinas in Attiki, Greece. Ion ratio confirmation was used for the identification of the compounds.
\end{abstract}

Key words: Optimization strategy, Electrospray ionization, Atmospheric pressure chemical ionization, Phenylureas, Triazines, 3,4-Dichloroaniline, DOE (Design of Experiments), Ion ratio confirmation, Matrix effect, Solvent effect

\section{Introduction}

T rgarol 1051 and Diuron are two of the most frequently 1 used booster biocide agents, added in copper-based antifouling paints, applied in surfaces submerged in water to prevent biofouling [1]. Irgarol 1051 (2-methylthio-4-tertbutylamino-6-cyclopropylamino-s-triazine) is a symmetrical

Electronic supplementary material The online version of this article (doi:10.1007/s13361-011-0191-z) contains supplementary material, which is available to authorized users.

Correspondence to: Nikolaos S. Thomaidis; e-mail: ntho@chem.uoa.gr triazine, and its principal degradation product is M1 (2methylthio-4-tert-butylamino-s-triazine), resulting from $\mathrm{N}$ dealkylation through biodegradation, photodegradation, and chemical hydrolysis [2-4]. Diuron [1-(3,4-dichlorophenyl)3,3-dimethyl urea] is a substituted urea and degrades by $\mathrm{N}$ demethylation under aerobic conditions to DCPMU [1-(3,4dichlorophenyl)-3-methyl urea], DCPU [1-(3,4-dichlorophenyl) urea] and DCA (3,4-dichloroanliline) [5].

The toxicity of the six compounds is, in decreasing order, Irgarol 1051 $>$ Diuron $>$ M1 $>$ DCPMU $>$ DCA $>$ DCPU for the green alga Dunaliella tertiolecta and Irgarol 1051 $>$ Diuron $>$ M1 $>$ DCA for the diatom Navicula forcipata; the most toxic 
compound, Irgarol 1051, has an $\mathrm{EC}_{50}$ value equal to $0.6 \mu \mathrm{g} / \mathrm{L}$ [6]. Phenylureas and triazines have also endocrine-disrupting effects [7, 8], and Diuron is already on the European Union endocrine disrupting compounds (EDCs) priority list [9]. Although the exact endocrine disruption properties of these compounds are ambiguous, there are indications that Diuron possesses AhR-mediated transactivation effect in vivo, as well as in vitro, AhR being a ligand-dependent transcription factor that regulates genes involved in xenobiotic metabolism, cellular proliferation, and differentiation [10]. Additionally, another assay for the androgenic or anti-adrogenic activity of various phenylurea herbicides has shown that Diuron, DCA, and DCPU have the ability to interact with the bovineandrogen receptor [11]. Furthermore, Irgarol 1051, and M1 to a lesser extent, affect the development of sea urchin [12].

The wide use of Irgarol 1051 and Diuron in the past, and the potential adverse effects of these antifouling biocides and their metabolites on the marine ecosystem, and consequently on humans through the food chain, has raised increased interest for the monitoring of these compounds. Therefore, a number of analytical methods were developed for their determination in several environmental matrices. Diuron, Irgarol 1051, and its degradation product, M1, can be determined simultaneously by HPLC-DAD $[13,14]$ and LC-MS/MS $[15,16]$. Diuron and one of its degradation products can be determined by LC-MS/MS in sewage sludge [17] and water [18]. However, Diuron and all of its three products have been determined only by LC single quadrupole MS in water [19]. Both target compounds, Diuron and Irgarol 1051, and all of their degradation products have been determined simultaneously only by HPLC-DAD in water and sediments $[13,14]$. Especially for the dichloroaniline (DCA) molecule, a poor signal is obtained with LC-ESI-MS/ MS and, therefore, derivatization with pentafluoropropionic anhydride has been proposed before LC-MS/MS analysis of
3,5-DCA in human urine [20]. For the same matrix and analysis, HPLC with an electrochemical detector [21] and GC-MS were also applied [22].

Considering the above, the principal aim of this study is the successful ionization of DCA for the first time with atmospheric pressure ionization techniques, without the need of derivatization, and following the development of confirmative and sensitive LC-MS/MS methods for the simultaneous determination of Irgarol 1051, Diuron and all their degradation products in water, sediment and mussel. To accomplish that, comparisons of ESI and APCI were made in the positive- and negative-ion modes, and the effect of the mobile phase on ionization was evaluated for both techniques. An "experimental design" approach was applied for the optimization of the ESI and APCI parameters (i.e., mobile phase flow rate, drying gas flow rate, nebulizer gas pressure, probe positioning, ion-transfer tube temperature, vaporizer temperature, and discharge current), and an optimization strategy for the entire LC-API-MS/MS method is proposed for the development of such methods.

The sample preparation of water, sediment and biota samples usually consists of several preconcentration and purification steps because the concentration levels of these compounds are low and the complexity of these matrices is high. Solid-phase extraction (SPE) [13, 14, 16-19] is the most commonly applied technique. Therefore, the second objective of this study is to minimize sample preparation steps. A fast, generic, sample preparation is proposed for the determination of Irgarol 1051, Diuron, and their degradation products in sediments and mussels, comprising only solvent extraction. The method was validated by using spiked environmental samples, and ion ratios of confirmation/quantitation SRM transitions were compared between standards and the different matrices and used as confirmative criteria. Finally, the method was applied to samples obtained from the Greek marine environment.

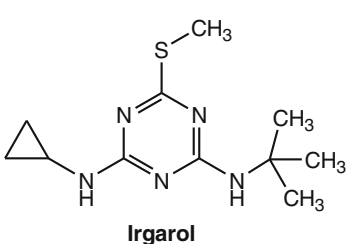<smiles>CNC(=O)Nc1ccc(Cl)c(Cl)c1</smiles>

DCPMU<smiles>CN(C(=O)O)C(=O)Nc1ccc(Cl)c(Cl)c1</smiles>

Diuron-d6<smiles>CN(C)C(=O)Nc1ccc(Cl)c(Cl)c1</smiles>

Diuron<smiles>NC(=O)Nc1ccc(Cl)c(Cl)c1</smiles><smiles></smiles><smiles>CSc1nc(N)nc(NC(C)(C)C)n1</smiles><smiles>Nc1ccc(Cl)c(Cl)c1</smiles>

DCA 


\section{Experimental}

\section{Standards and Materials}

Standards of Irgarol 1051, Diuron, and its degradation products, DCPMU, DCPU, and DCA, were supplied by Dr. Ehrenstorfer GmbH (Augsburg, Germany), and M1 was a gift of Additive Hellas Ltd. (Halkidona, Greece). The deuterated internal standards Diuron- $\mathrm{d}_{6}$ and Atrazine- $\mathrm{d}_{5}$ were purchased from Sigma-Aldrich (Sheboygan Falls, WI, USA). Methanol (MeOH) and acetonitrile (ACN) of LC-MS grade were obtained from LABSCAN (Dublin, Ireland), and formic acid (HCOOH) of LC-MS grade was obtained from Fluka (Buchs, Switzerland). Water was purified with a MilliQ water system (Millipore, Bedford, MA, USA).

Isolute silica-based bonded $\mathrm{C} 18$ solid-phase extraction cartridges $(500 \mathrm{mg}, 6 \mathrm{~mL})$ and Florisil SPE cartridges $(500 \mathrm{mg}, 3 \mathrm{~mL})$ were supplied by International Sorbent Technologies (Caerthphilly, UK). The centrifuge used was a Hettich, ROTOFIX 32 (Tuttlingen, Germany). Stock solutions in the concentration range of 100 to $1000 \mu \mathrm{g} / \mathrm{mL}$ of each compound were prepared in methanol and used for further dilutions. The stock solutions were found to be stable for at least 1 year at $-15^{\circ} \mathrm{C}$. Working standard solutions were daily prepared in mobile phase.

\section{Strategy of LC-MS/MS Optimization}

The development of an LC-MS/MS method for the determination of different compounds can be a tedious task because numerous parameters are involved, affecting in various ways the response. In addition, instruments of different manufacturers possess specific electronic and geometrical designs and demand special settings. Therefore, the simple application of an already published method is not always successful. There are various published optimization strategies for the development of LC-MS and tandem MS methods [23-26], and a tutorial for statistical design of experiments especially for mass spectrometry [27] offers useful guidelines. However, each analytical problem is unique and demands a particular approach.

Herein, we propose a different approach, including the selection of the atmospheric pressure ionization mode, for the development and optimization of an LC-MS/MS method. The strategy consists of discrete steps and loops. An "experimental design" strategy is also applied as a mathematical tool for the optimization of ESI and APCI parameters, so that potential interaction between the variables can be identified. A schematic of the ion source of the instrumentation used is depicted in Figure 1 and the plan of the optimization strategy that was followed is depicted in Figure 2. The first issue to address was the selection of the ionization mode (ESI or APCI) that provides and enhances most the formation of protonated or deprotonated ions of the target compounds, with special attention to 3,4-DCA. Comparison of the two ionization modes was conducted under positive and negative polarity with mobile phase mixtures of $\mathrm{MeOH} / \mathrm{H}_{2} \mathrm{O}(60: 40)$ and $\mathrm{ACN} / \mathrm{H}_{2} \mathrm{O}$

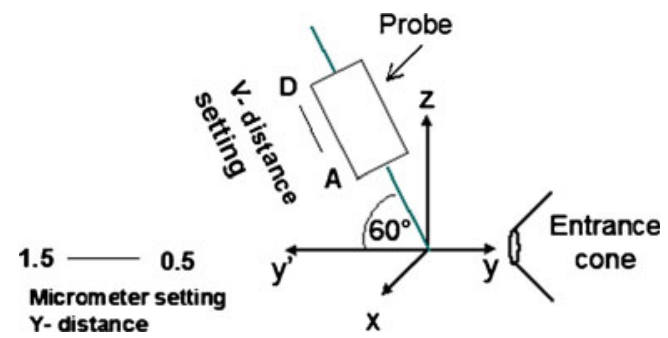

Figure 1. Schematic of the ionization source of the LC-MS/ MS (Thermo TSQ Quantum Access) instrumentation used

(60:40) containing formic acid from 0 to $0.5 \%$. Methanolic standard solutions of each compound $(1-3 \mu \mathrm{g} / \mathrm{mL})$ were measured twice by flow injection analysis (FIA) at $50 \mu \mathrm{L} / \mathrm{min}$ flow rate for ESI and $100 \mu \mathrm{L} / \mathrm{min}$ flow rate for APCI. The pattern of the mass spectra and the response factors, defined as the peak area of the reconstructed SIM chromatograms of the protonated ions (positive ionization) and deprotonated ions (negative ionization) divided by the tested concentration, for every compound were evaluated for the different conditions. At this point, the basic conditions that provide satisfactory response of the molecular ions for all the compounds, namely the ionization technique and the mobile phase, are defined. This initial step was very important for DCA, which provides signal only at special conditions. After this point, further optimization of the analyte responses can be performed.

After the selection of the ionization technique and polarity, gradient elution was optimized in order to have sufficient chromatographic resolution (The need for chromatographic resolution is discussed in Sections Optimization of LC-ESI-MS/ MS Method and Optimization of LC-APCI-MS/MS Method). The starting point of the gradient elution optimization was the mobile phase that gave the highest intensities from the previous

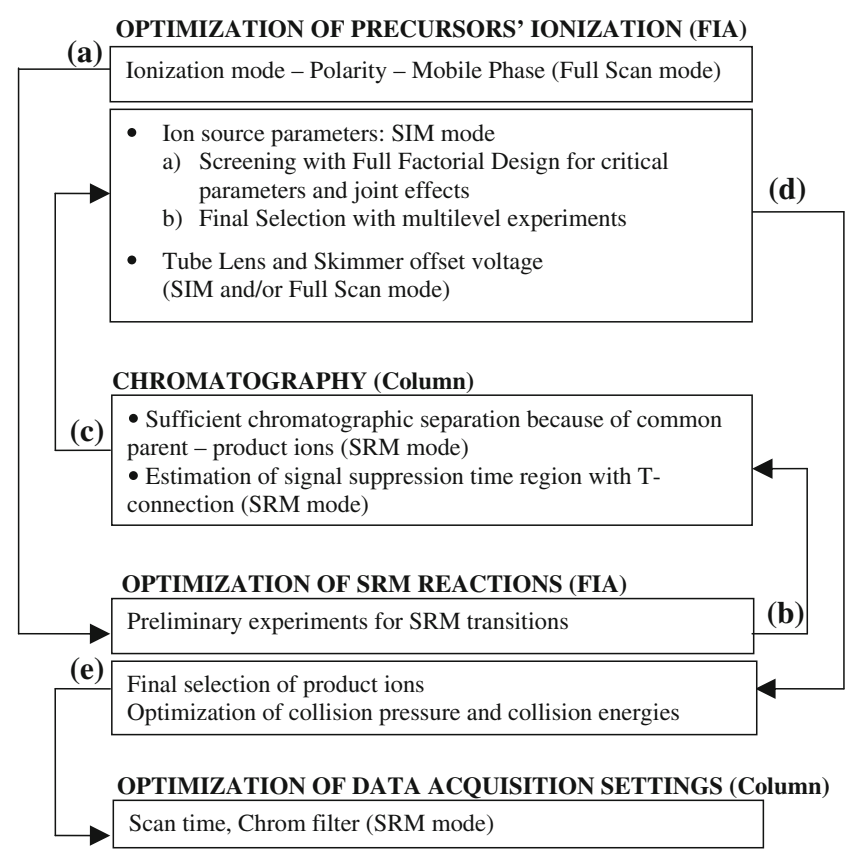

Figure 2. Optimization strategy plan 
step. During the optimization of separation, the monitored signals were the SRMs of the compounds, which were obtained during preliminary experiments by direct infusion to the ion source. At this stage signal suppression experiments were conducted with environmental sample extracts in order to estimate the elution time region of the matrix and check whether analytes and matrix components coelute.

Having defined the composition of the mobile phase entering the ion source, the operating parameters of the source were optimized according to experimental design with flow injections to the selected mobile phase. First, screening experiments were realized according to a full factorial experimental design in order to see which parameters are more critical. Afterwards, additional multilevel experiments were performed to locate the optimal values of those parameters. The SIM mode was applied for monitoring the signals of the protonated molecules.

The next step focused on the potentials of the region that lies between the ion transfer tube and the mass analyser, namely the tube lens and the skimmer offset voltages. The tube lens is of the same polarity with the ions of interest and serves to focus the ion beam towards the opening of the skimmer. The application of skimmer offset voltage, which is of opposite polarity, can be used for in-source collision induced dissociation (CID) of solvent adduct ions. However, its value needs optimization since at higher energies, molecular ions can fragment.

After maximizing the molecular ions' intensities, the SRM transitions were optimized. Two characteristic product ions of each compound with high intensities were selected and the collision pressure of Ar and the collision energy of each transition were optimized. The method development was completed with the optimization of the SRM data acquisition settings of the software, under the optimum conditions, by injections of a standard mixture solution of a low concentration $(0.1 \mathrm{ng} / \mathrm{mL}$ for triazine and $1 \mathrm{ng} / \mathrm{mL}$ for phenylurea and DCA) on the column. The settings that were optimized were the scan time for each SRM reaction (0.01$0.04 \mathrm{~s}$ ) and the chromatography filter, which is a noise reduction algorithm that smoothes peak profiles at low sample concentrations in chromatographic data (0-12 arbitary units). For the experimental design and the data statistical treatment, the STATGRAPHICS Centurion XV software package (Stat Point, Inc., Warrenton, Virginia, USA, ver. 2002) was used.

\section{LC-MS/MS Measurements}

The LC-MS/MS measurements were performed with a Thermo TSQ Quantum Access triple quadrupole mass analyzer connected to a UHPLC Accela pump and autosampler (San Jose, CA, USA). Liquid chromatography was performed with a Thermo C18 Hypersil Gold $(50 \mathrm{~mm} \times$ $2.1 \mathrm{~mm}, 1.9 \mu \mathrm{m}) \mathrm{LC}$ column, the column oven temperature was set at $25^{\circ} \mathrm{C}$ and the injection volume at $10 \mu \mathrm{L}$. Both ESI and APCI optimized methods used positive ionization.
For the ESI mode the optimized parameters were as follows: gradient elution with a mobile phase consisting of $0.2 \%$ formic acid in water (solvent $\mathrm{A}$ ) and $0.2 \%$ formic acid in $\mathrm{ACN}$ (solvent B) at a flow rate of $150 \mu \mathrm{L} / \mathrm{min}$. The gradient elution started at $\mathrm{A} / \mathrm{B} 55: 45$, changed linearly to $\mathrm{A} / \mathrm{B}$ 40:60 in $3 \mathrm{~min}$ and at 3.01 min returned to the initial conditions and remained there for equilibration up to 7 th min. The spray voltage was held at $4 \mathrm{kV}$. The sheath gas $\left(\mathrm{N}_{2}\right)$ pressure was $60 \mathrm{psi}$, the auxiliary gas $\left(\mathrm{N}_{2}\right)$ pressure was 27 units $(\sim 8 \mathrm{~L} / \mathrm{min})$ and the ion transfer capillary temperature was set at $270{ }^{\circ} \mathrm{C}$. The probe was set at 0.55 position of the micrometer $(\sim 1.4 \mathrm{~cm}$ from the entrance cone) for Y-distance and at position $\mathrm{D}$ for $\mathrm{V}$-distance (Figure 1). The skimmer offset was set at $-10 \mathrm{~V}$ for all the analytes and the tube lens voltage values for each one are presented in Table 1. Data were acquired in SRM mode with two transitions per analyte. The collision gas (Ar) pressure was $1.6 \mathrm{mTorr}$ and the SRM transitions with the collision energy voltages are presented in Table 1. The scan time for each SRM reaction was $0.02 \mathrm{~s}$ and the chromatography filter was set at 10 .

For the APCI mode the optimized parameters were as follows: gradient elution with a ternary mobile phase consisting of water (solvent $\mathrm{A}$ ), $\mathrm{MeOH}$ (solvent $\mathrm{B}$ ), and $\mathrm{ACN}$ (solvent $\mathrm{C}$ ) at a flow rate of $150 \mu \mathrm{L} / \mathrm{min}$. The gradient elution started at $\mathrm{A} / \mathrm{B} / \mathrm{C} 55: 10: 35$, changed linearly to $\mathrm{A} / \mathrm{B} / \mathrm{C}$ 40:10:50 in $3 \mathrm{~min}$, remained at these conditions until the 4 th min and at $4.01 \mathrm{~min}$ returned to the initial conditions $\mathrm{A} / \mathrm{B} / \mathrm{C}$ 55:10:35 until the 8th min. Corona discharge current was held at $3.5 \mu \mathrm{A}$. The sheath gas pressure was $40 \mathrm{psi}$, the auxiliary gas pressure was 30 units (approx. $9 \mathrm{~L} / \mathrm{min}$ ), the vaporizer temperature was set at $300{ }^{\circ} \mathrm{C}$ and the ion transfer capillary temperature at $150{ }^{\circ} \mathrm{C}$. The probe was set at 1.5 position of the micrometer ( $\sim 3.8 \mathrm{~cm}$ from the entrance cone) for Y-distance and at position $\mathrm{C}$ for $\mathrm{V}$-distance (Figure 1). The skimmer offset was set at $-10 \mathrm{~V}$ for triazines and DCPMU, $-15 \mathrm{~V}$ for DCA and DCPU, whereas no skimmer was applied for Diuron and Diuron- $\mathrm{d}_{6}$. The tube lens voltage values for each analyte are presented in Table 1 and the rest of the SRM parameters are the same with those used for the ESI method.

Instrument mass calibration and sensitivity was controlled by tuning with polytyrosine-1,3,6 solution provided by the manufacturer. Additionally, standard solutions of low and high concentrations were measured at every set of measurements. Data handling was performed with Xcalibur 2.0.6 software.

\section{Sample Preparation}

The methods were applied to water, sediment, and mussel samples that had been cleaned-up by SPE, and to sediment and mussel samples that had not been subjected to any clean-up. Purification of marine sediments, water samples (sea water and tap water) and mussels was performed according to already reported optimized methods $[13,14,28]$, respectively, and the exact procedures are described in detail in Online Resource (Sample preparation). The sample preparation for the sediments and mussels that is proposed by the present study and 
Table 1. SRM Acquisition Parameters

\begin{tabular}{|c|c|c|c|c|}
\hline Compound & SRM transition & Collision energy (V) & Tube lens ESI (V) & Tube lens APCI (V) \\
\hline \multirow[t]{2}{*}{ Diuron } & $233 \rightarrow 72(\mathrm{Q})$ & 17 & 100 & 96 \\
\hline & $\rightarrow 46(\mathrm{C})$ & 15 & & \\
\hline Diuron- $\mathrm{d}_{6}$ & $239 \rightarrow 78$ & 20 & 76 & 103 \\
\hline \multirow[t]{2}{*}{ DCPMU } & $219 \rightarrow 127(\mathrm{Q})$ & 28 & 93 & 101 \\
\hline & $\rightarrow 162(\mathrm{C})$ & 14 & & \\
\hline \multirow[t]{2}{*}{ DCPU } & $205 \rightarrow 127(\mathrm{Q})$ & 26 & 94 & 112 \\
\hline & $\rightarrow 162(\mathrm{C})$ & 13 & & \\
\hline \multirow[t]{2}{*}{ DCA } & $162 \rightarrow 127(\mathrm{Q})$ & 19 & 97 & 106 \\
\hline & $\rightarrow 109$ (C) & 30 & & \\
\hline \multirow[t]{2}{*}{ Irgarol 1051} & $254 \rightarrow 198(\mathrm{Q})$ & 18 & 87 & 101 \\
\hline & $\rightarrow 108(\mathrm{C})$ & 29 & & \\
\hline \multirow[t]{2}{*}{ M1 } & $214 \rightarrow 158(\mathrm{Q})$ & 16 & 87 & 105 \\
\hline & $\rightarrow 68(\mathrm{C})$ & 36 & & \\
\hline Atrazine- $\mathrm{d}_{5}$ & $221 \rightarrow 179$ & 17 & 87 & 93 \\
\hline
\end{tabular}

does not include any clean-up step is as follows: $0.2 \mathrm{~g}$ of dry marine sediments and freeze-dried mussels were spiked with $20 \mu \mathrm{L}$ of $50 \mathrm{ng} / \mathrm{mL}$ Atrazine- $\mathrm{d}_{5}$ and $40 \mu \mathrm{L}$ of $100 \mathrm{ng} / \mathrm{mL}$ Diuron- $\mathrm{d}_{6}$. For the construction of matrix calibration curves, the recovery study and the method validation, the samples were also spiked with the appropriate aliquot of a $100 \mathrm{ng} / \mathrm{mL}$ mix standard solution. Next, $1 \mathrm{~mL}$ of ACN was added as the extraction solvent and the mixture was vortexed for $30 \mathrm{sec}$ and then ultrasonicated for $30 \mathrm{~min}$. The ACN extract was separated from the solid phase by centrifugation at $3500 \mathrm{rpm}$ for $10 \mathrm{~min}$ and was then transferred to another tube. Afterwards, $0.4 \mathrm{~mL}$ of the extract was diluted with $0.2 \mathrm{~mL}$ of $0.2 \%$ aqueous $\mathrm{HCOOH}$ in an autosampler vial. Standard solutions were prepared with the same procedure without the addition of matrix. All samples were filtered with PET syringe filters with pore size $0.22 \mu \mathrm{m}$ and $13 \mathrm{~mm}$ diameter (Macherey-Nagel) before measurement with LC-MS/MS.

\section{Signal Suppression Experiments}

In order to qualitatively estimate the signal suppression in ESI and APCI caused by the different matrices with and without clean-up, a configuration of syringe pump "tee-ed" into the HPLC effluent line for post-column addition of standard solution was used. In detail, a mix standard solution of $200 \mathrm{ng} / \mathrm{mL}$ (for each analyte) was continuously infused at a flow rate of $5 \mu \mathrm{L} / \mathrm{min}$ through the syringe pump into the mobile phase flow, while the SRM reactions were monitored for all the compounds, resulting in constant SRM signals. Solvent and samples were injected into the column and run by the optimized ESI and APCI methods.

\section{Method Validation}

The linearity of the response of the LC-ESI-MS/MS system versus analyte concentrations was examined with calibration curves, obtained by measuring seven standard solutions with concentration levels ranging between 0.05 and $50 \mathrm{ng} / \mathrm{mL}$ for Irgarol 1051 and M1, and 0.5 to $100 \mathrm{ng} / \mathrm{mL}$ for Diuron and its three degradation products. The working solutions were prepared in mobile phase and also contained 5.0 and $20 \mathrm{ng} /$
$\mathrm{mL}$ of Atrazine- $\mathrm{d}_{5}$ and Diuron- $\mathrm{d}_{6}$, respectively. Similar experiments were conducted for the LC-APCI-MS/MS method, but with standard solutions of higher concentration levels (1$100 \mathrm{ng} / \mathrm{mL}$ ) because of the lower sensitivity. Matrix calibration curves were constructed with sea water samples spiked at 0.5 , $1.0,1.5$, and $2.0 \mathrm{ng} / \mathrm{mL}$ and with sediments and mussels prepared without clean-up spiked at 5,10,15 and $20 \mathrm{ng} / \mathrm{g}$.

The instrumental limits of detection (for ESI and APCI) were defined as $(3 \times \mathrm{SD}) / b$, where $\mathrm{SD}$ was the standard deviation of the response of ten replicate analyses of the lowest working standard solution of the calibration curve and $b$ was the slope of the curve. These values were experimentally confirmed. The method LOD for the different environmental samples was defined as the concentration of the analyte in matrix that was equal to three times the average level of the baseline noise close to the peak. The method LOQ was defined as the concentration that was 10 times the same noise level. The recovery $\mathrm{R}(\%)$ was calculated according to the following equation (Equation 1), where the concentration of the standard solution was equal to the concentration spiked to the sample. The precision of the method in the different matrices was expressed as \%RSD of the recovery obtained from six replicates.

$\mathrm{R}(\%)=\frac{\text { signal from spiked sample }- \text { signal from unspiked sample }}{\text { signal from standard solution }} \times 100$

Additionally, the peak area ratios of the quantitation SRM/confirmation SRM were calculated from standard solutions and compared to the corresponding values obtained from the different spiked matrices.

\section{Results and Discussion}

\section{Comparison of ESI and APCI under Positive and Negative Polarity Effect of Mobile Phase on Ionization}

For the study of the ionization of the compounds, data were acquired in full scan mode $(\mathrm{m} / \mathrm{z} 50-300)$ and the quantifi- 
cation was based on the peak area of the reconstructed SIM chromatograms of the molecular ions. Qualitative and quantitative evaluation of spectra is discussed in the following paragraphs.

For $\operatorname{ESI}(+)$ the most remarkable observation was that the response factor of DCA was 60-fold higher with the presence of ACN compared with that with $\mathrm{MeOH}$ (Online Resource, Figure S1). The response factors of the rest of the compounds were affected to a lesser extent. The positive effect of ACN on DCA ESI-MS signal, comparing to $\mathrm{MeOH}$, has been described previously [19], but without providing any explanation. According to the Thomson and Iribarne study [29], during the intermediate stages of separation of a cluster ion from the mother droplet, the cluster ion can deform or become polarized under the influence of the field by shifting and reorientation of the solvent molecules. This adaptability of the cluster might lower appreciably the energy barrier that the ion must overcome to reach the gas phase [29]. Taking into consideration that DCA is a small and basic compound with dissociation constant pKa of 2.968 [30] and that $\mathrm{MeOH}$ is a proton donor solvent type, whereas $\mathrm{ACN}$ is characterised mainly by dipole-dipole interactions, it could be assumed that the cluster with $\mathrm{MeOH}$ is more rigid and less prone to adaptation because of stronger intermolecular interactions between $\mathrm{MeOH}$ and DCA, probably because of H-bonding, prohibiting the protonated ion of DCA to be transferred from the droplets to the gas phase. On the contrary, for the corresponding cluster of the protonated DCA with ACN it could be speculated that it undergoes deformation and polarization more easily, lowering appreciably the energy barrier and permitting the ion of DCA to be transferred to the gas phase.

DCA also formed solvent adducts with ACN $[\mathrm{M}+41+1]^{+}$ at high abundance as shown in mass spectrum of Figure 3. The same was observed for DCPU and to a lesser extent for DCPMU. Additionally, sodium adducts $[\mathrm{M}+23]^{+}$of DCPMU, Diuron, and Diuron- $\mathrm{d}_{6}$ were formed when $\mathrm{MeOH} / \mathrm{H}_{2} \mathrm{O}$ was used.

The addition of formic acid in the mobile phase significantly improved the response factors of all the compounds in both solvents, particularly for DCA and Atrazine- $\mathrm{d}_{5}$, having an optimum for its concentration (Online Resource, Figure S1). Additionally, formic acid eliminated sodium adducts.

For $\mathrm{APCI}(+)$ the nature of organic solvent affects the ionization of the compounds in a different way than it does in ESI. The response factors obtained with $\mathrm{MeOH}$ are higher than those obtained with ACN, especially for phenylureas, DCA and Atrazine- $\mathrm{d}_{5}$ (Online Resource Figure S2). The better performance of APCI with $\mathrm{MeOH}$ can be explained considering the gas-phase acid-base reactions between molecules of the solvents in the mobile phase and the analyte molecules, and the fact that $\mathrm{MeOH}$, when protonated is a better reagent ion than protonated ACN [31, 32]. Furthermore, solvent adducts of ACN with DCA, DCPU and DCPMU were also present in
APCI $(+)$ spectra as in ESI (+). The addition of formic acid had no significant impact, as expected, since during APCI ionization takes place in the gas phase.

In $\operatorname{ESI}(-)$, the compounds that gave satisfactory response for the deprotonated ions $[\mathrm{M}-\mathrm{H}]^{-}$and clear spectra were Diuron, DCPMU, and DCPU with most abundant $\mathrm{m} / \mathrm{z}$ ions 231,217 , and 203, respectively. Generally, there were no statistically significant differences among the tested mobile phases. The best results for the three compounds were obtained with $\mathrm{MeOH}-0.04 \% \mathrm{HCOOH}$. In APCI(-) none of the compounds produced a clear spectrum.

Table 2 summarizes the standardised response factors under the optimum mobile phase for each ionization mode and polarity. The standardization for Diuron- $\mathrm{d}_{6}$, DCPMU, DCPU, and DCA was based on the signal of Diuron and for M1 and Atrazine- $\mathrm{d}_{5}$ on the signal of Irgarol 1051. The corresponding signal to noise ratios that were given by XCalibur software according to ICIS peak detection algorithm are presented in Online Resource (Table S1), and it can be observed that they are in accordance with the data obtained from the response factors. From these data it becomes obvious that the most suitable ionization technique for all analytes is $\operatorname{ESI}(+)$. However, it should be mentioned that in another LC-MS study, $\mathrm{APCI}(+)$ has been reported to be more sensitive than ESI $(+)$ for triazines and phenylurea herbicides [33]. This could be attributed to the different instrumentation used.

\section{Optimization of LC-ESI-MS/MS Method}

The LC mobile phase that was initially selected for ESI was a mixture of $\mathrm{ACN}$ - water containing $0.2 \%$ ( $\mathrm{vol} / \mathrm{vol}$ ) $\mathrm{HCOOH}$ according to the results of Figure S1 in Online Resource. Injections of individual standard solutions of the compounds on the column revealed that DCPU and DCPMU gave signal in the SRM chromatogram of DCA $(162>127)$. Possibly, $\mathrm{m} / \mathrm{z} 162$ is formed by source collision induced dissociation of DCPU and DCPMU and afterwards it fragments to DCA product ion $(\mathrm{m} / z$ 127) in the collision cell. Furthermore, DCA gave signal in the SRM chromatogram of DCPU $(205>127)$. This was attributed to the fact that the molecular ion of DCPU has the same $m / z$ (205) with the solvent adduct of the isotope of DCA $\left[\mathrm{DCA}\left({ }^{37} \mathrm{Cl}\right)+\right.$ $\mathrm{ACN}+\mathrm{H}]^{+}$, which is formed at high abundance (Figure 3); and at the same time, DCA and DCPU share the same product ion $(\mathrm{m} / \mathrm{z}$ 127). For the aforementioned reasons, chromatographic separation of DCA from DCPU and DCPMU was obligatory. Different gradient elution programs were tested and the final gradient profile is described in the Experimental section (Online Resource, Figure S3).

For the ESI parameters optimization, screening experiments were realised first according to a full factorial experimental design in order to determine which parameters are the most critical. The experimental factors were the Y-distance (positions $0.5-1.5$ of the micrometer that correspond to $\sim 1.4-3.8 \mathrm{~cm}$ from the entrance cone) and the V-distance (positions $\mathrm{C}-\mathrm{D}$ ) 


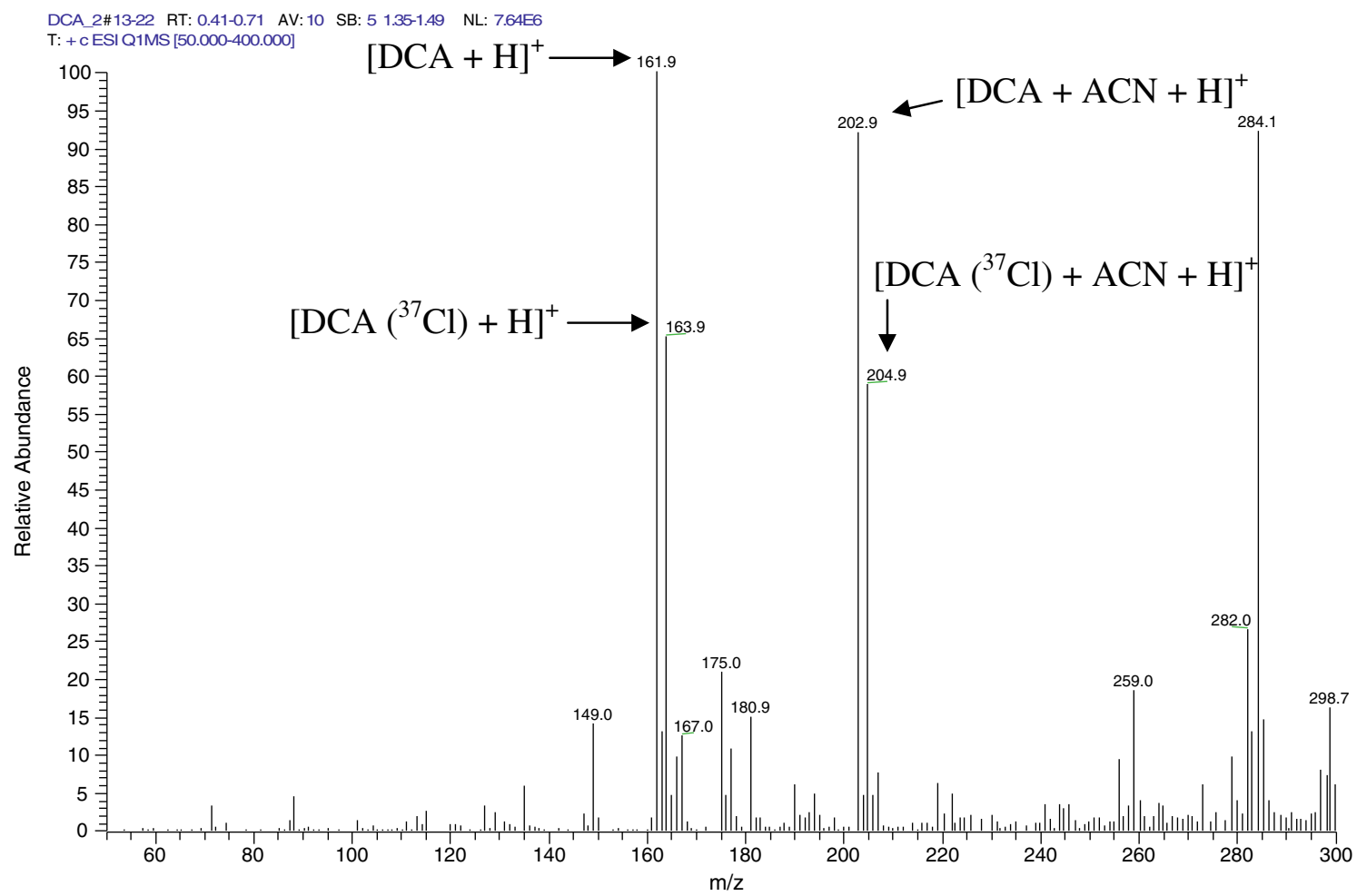

Figure 3. Mass spectrum of DCA with mobile phase $\mathrm{ACN}$-water with $0.2 \% \mathrm{HCOOH}$

between the ESI needle tip and the entrance cone (Figure 1), the sheath gas pressure (20-60 psi), the auxiliary gas pressure (540 arbitrary units that correspond to $\sim 1.5-12 \mathrm{~L} / \mathrm{min}$ ), and the ion transfer capillary temperature $\left(150-350{ }^{\circ} \mathrm{C}\right)$ at the two indicated levels. The response variables were the peak areas of the protonated ions. Therefore, a two-block full factorial design $2^{5}+1$ center point for each block was created, proposing 34 experiments in a randomized order. This design was applied to a mixture of standard solution diluted in the mobile phase and containing $200 \mathrm{ng} / \mathrm{mL}$ of the analytes and the two internal standards. The standardized pareto charts for all the compounds are illustrated in Online Resource (Figure S4). A first-order model was fitted to each set of data and the good fit of the model was evaluated by the statistic $\mathrm{R}^{2}$ of the ANOVA, which ranged from $90 \%$ for Diuron up to $96 \%$ for Atrazine- $\mathrm{d}_{5}$.

From the variability of the pareto charts it can be concluded that the effect of the ESI parameters tested on the ionization is very much compound-dependent. However, it can be observed that Y-distance is a critical factor for all the compounds and, for the majority of them, is the most critical one. In particular, the shorter the distance, the higher the signal. On the contrary, V-distance does not affect the output signal. The ion transfer capillary temperature is also a critical factor for the majority of the compounds. The sheath gas and the auxiliary gas pressure are among the critical factors as well, but with a lower effect. It should be noted that DCA signal is significantly affected (Standardized effect $>4$ ), by also the auxiliary gas flow rate in such a way (positive effect) that indicates that this compound needs more intense conditions for desolvation comparing to the others, which is in accordance with the previous discussion. In the pareto charts, a number of joint effects can be identified that involve the four aforementioned critical parameters. However, the most frequent and with the highest

Table 2. Standardized Response Factors in Optimum Mobile Phases

Standardized Response Factors

\begin{tabular}{lcccc} 
& ESI $(+)$ & ESI $(-)$ & APCI $(+)$ & APCI $(-)$ \\
\hline Diuron & 100 & 2 & 14 & 0 \\
Diuron-d & 93 & n.a. & 14 & n.a. \\
DCPMU & 60 & 2 & 12 & 0 \\
DCPU & 24 & 0 & 4 & 0 \\
DCA & 26 & 0 & 3 & 0 \\
Irgarol 1051 & 100 & 0 & 3 & 0 \\
M1 & 76 & 0 & 5 & 0 \\
Atrazine-d & 66 & & & 0 \\
\hline
\end{tabular}

n.a. not applicable 
impact is the interaction between the ion transfer capillary temperature and auxiliary gas pressure (Online Resource, Figure S4, DE joint effect).

The screening experiments were followed by a rotatable and orthogonal central composite design $2^{4}+$ star point, consisting of 36 experiments. The experimental factors were the four factors that were found to be critical during the screening experiments and the response variables were the $\mathrm{MH}^{+}$peak areas. The applied levels of the CCD are presented in Online Resource (Table S2). A second-order model was fitted to the data and the $\mathrm{R}^{2}$ ranged from $95 \%$ for Atrazine- $\mathrm{d}_{5}$ up to $98 \%$ for M1. The analysis of each set of data showed that the optimum values for Y-distance and sheath gas pressure was the same for all the compounds, whereas the optimum values of the capillary temperature and the auxiliary gas flow rate varied. Moreover, it was shown that these two factors interact. Therefore, in order to examine in more detail their effect, contour plots were created for each peak area as a function of capillary temperature and auxiliary gas flow rate, holding constant Y-distance and sheath gas pressure at their optimum values (Figure 4). The contour plot of DCA indicated that high flow rate of the auxiliary gas was necessary at any temperature, probably because of increased need of drying and desolvation of its droplets. On the contrary, the optimum area for DCPU was located towards the low values of temperature and middle to low values of auxiliary gas pressure. Moreover, these two compounds presented the lowest sensitivity; consequently the decision should be based mainly on their responses. Therefore multiple response optimization was performed for DCA and DCPU peak areas in order to achieve maximization of both responses simultaneously combined in one function (desirability). Figure 5 illustrates the corresponding estimated response surface.

The maximization of the precursor ions' intensities was completed with the optimization of tube lens and skimmer offset voltages. The optimization of these two parameters was performed separately for each compound by injections of standard solutions $(1-3 \mu \mathrm{g} / \mathrm{mL})$ to the defined mobile phase and flow rate. As it was stated previously, the application of skimmer offset voltage can be used for source collision induced dissociation (CID) of solvent adduct ions. This parameter proved to be very useful in the case of DCA and DCPU because of the intense solvent adducts with ACN (Figure 3), which were decreased significantly at the optimum value of the skimmer voltage.

For the selection of the SRM transitions, breakdown curves were produced for each precursor ion $\mathrm{MH}^{+}$in order to determine the fragmentation pattern of the compounds. The two most intense product ions were selected for each compound. The collision pressure was optimized for the three compounds with the lowest sensitivity (DCA, DCPU, and DCPMU) and was finally set at 1.6 mTorr. Then, the collision energy for each selected SRM transition was optimized at the defined collision pressure. The selected SRM transitions are summarised in Table 1.
The first SRM transition of Irgarol 1051 and M1 involves elimination of the tert-butyl group $\left[\mathrm{C}_{4} \mathrm{H}_{9}-\mathrm{H}\right]$, and elimination of the isopropyl group for Atrazine- $\mathrm{d}_{5}$, and was used for quantitation $(\mathrm{Q})$. The products of the second SRM transition of Irgarol 1051 and M1, used for confirmation (C), were assigned to ions generated from $\mathrm{MH}^{+}$by loss of the tert-butyl group $\left[\mathrm{C}_{4} \mathrm{H}_{9}-\mathrm{H}\right]$, the methylthio group $\left[\mathrm{HSCH}_{3}\right]$ and $\left[\mathrm{H}_{2} \mathrm{NCN}\right]$ by cleavage of the aromatic ring, according to proposed decomposition processes of s-triazines [34].

The fragmentation of Diuron involves elimination of the groups that contain the phenyl group, $\left[-\mathrm{NHC}_{6} \mathrm{H}_{3} \mathrm{Cl}_{2}\right]$ and $\left[-\mathrm{CONHC}_{6} \mathrm{H}_{3} \mathrm{Cl}_{2}\right]$ for the $(\mathrm{Q})$ and the $(\mathrm{C})$ transition, accordingly. On the contrary, fragmentation of DCPMU probably involves cleavage of the chain $\left[-\mathrm{CONHCH}_{3}\right]$ for (C) transition and additional elimination of one $\mathrm{Cl}$ for $(\mathrm{Q})$ transition. Similar fragmentation pattern can be proposed for DCPU, as well. Finally the fragmentation of DCA is estimated that involves elimination of $\mathrm{Cl}$ for $(\mathrm{Q})$ transition and additional elimination of $\mathrm{NH}_{3}$ for $(\mathrm{C})$ transition.

\section{Optimization of LC-APCI-MS/MS Method}

APCI optimization concerned maximization of precursors' abundances and liquid chromatography, while the rest of the conditions were the same as for ESI. Chromatographic parameters had to be re-optimized, because the mobile phase that enhanced most the atmospheric pressure chemical ionization was different from that in ESI and also because the optimum performance in APCI is considered to be at higher flow rates. Therefore, a modified strategy plan was followed that had an additional loop between the chromatography section and ion source parameters (Figure 2), according to a proposed optimization strategy for phytoestrogens by LC-MS [35].

The LC mobile phase that was initially selected for APCI was a mixture of $\mathrm{MeOH}$ - water according to the results presented in Online Resource (Figure S2). Injections of the individual standard solutions of the compounds on the column showed that Diuron, DCPMU and DCPU produced signal in the SRM of DCA. This was attributed to the fact that these three compounds fragment to DCA molecular ion $(\mathrm{m} / \mathrm{z} 162)$ by source collision induced dissociation in the APCI interface. Furthermore, these compounds coeluted, therefore chomatographic separation should be improved. Having as a starting point an isocratic elution with $\mathrm{MeOH} /$ water (60:40) different gradient and isocratic elution programs were tested. However, no gradient program with $\mathrm{MeOH}$-water could separate successfully Diuron and its degradation products. Successful resolution was achieved only with the addition of ACN in the mobile phase, an action that was initially avoided, because of signal suppression (Online Resource, Figure S2). The optimized gradient profile for the LCAPCI-MS/MS is given in the Experimental section.

For the APCI parameters optimization, screening experiments were realised first, as described for ESI. The experimental 


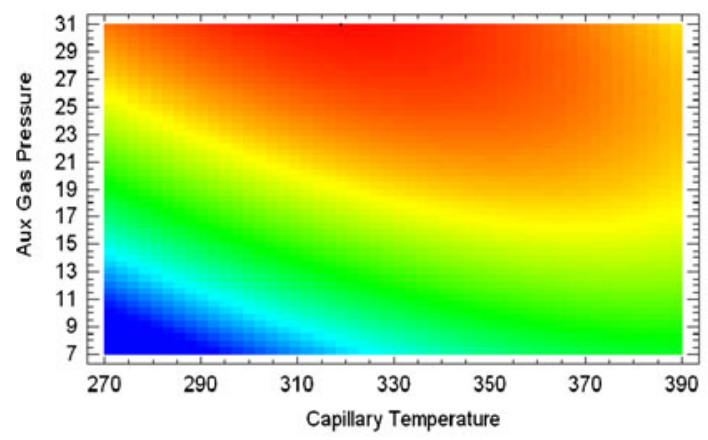

Area DCA

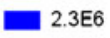

2.6E6

$2.9 \mathrm{E} 6$

$3.2 \mathrm{E} 6$

3.5E6

3.8E6

4.1E6

$4.4 \mathrm{E} 6$

$4.7 \mathrm{E} 6$

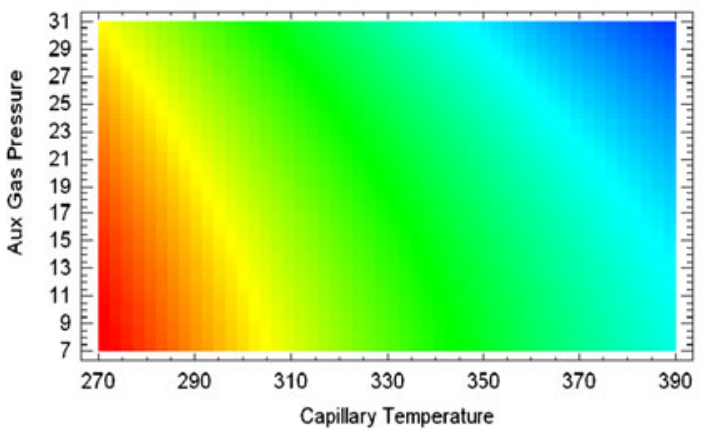

Area DCPU

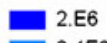

$2.4 \mathrm{E} 6$

$2.8 \mathrm{E} 6$

$3.2 \mathrm{E} 6$

$3.6 \mathrm{E} 6$

4.E6

4.4E6

$4.8 \mathrm{E} 6$

$5.2 \mathrm{E} 6$
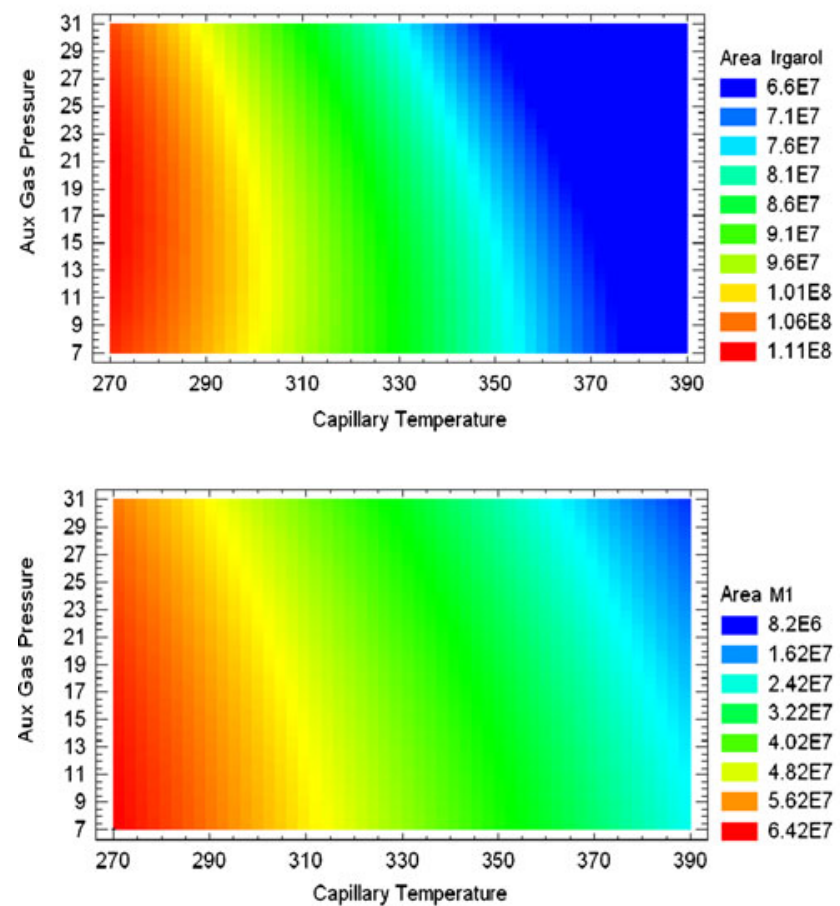
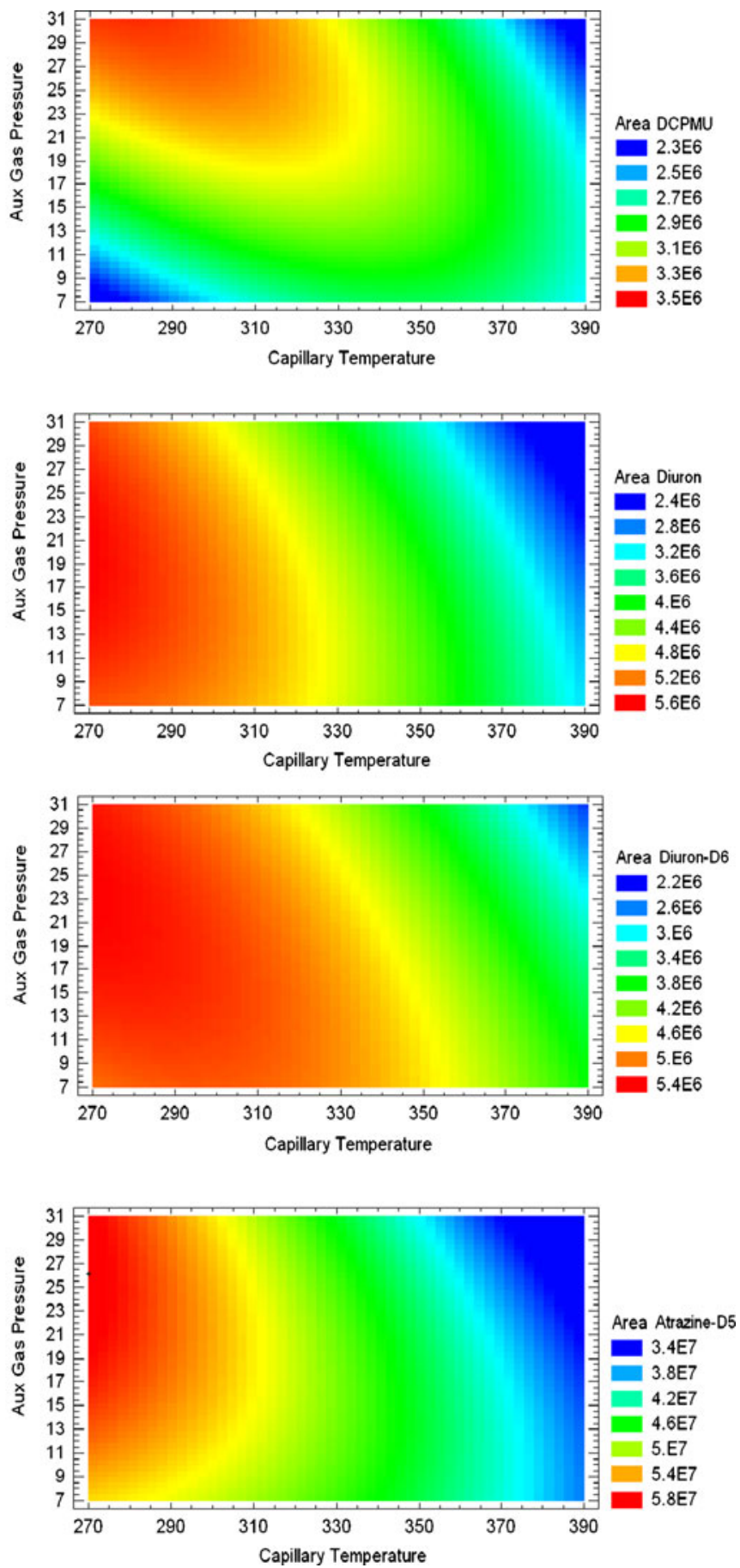

Figure 4. Contour plots of $[\mathrm{M}+1]^{+}$peak areas in ESI as a function of capillary temperature and auxiliary gas flow rate. $\mathrm{Y}$ distance (micrometer position): 0.55, sheath gas pressure: 60 psi

factors were the flow rate of the mobile phase $(0.1-1 \mathrm{~mL} / \mathrm{min})$, the vaporiser temperature $\left(300-450{ }^{\circ} \mathrm{C}\right)$, the sheath gas pressure (20-40 psi), the auxiliary gas pressure (5-25 arbitrary units that correspond to $\sim 1.5-7.5 \mathrm{~L} / \mathrm{min}$ ), the ion transfer capillary temperature $\left(150-350^{\circ} \mathrm{C}\right)$, and the discharge current $(3-8 \mu \mathrm{A})$ at the two indicated levels. The response variables were the peak areas of the protonated ions. Therefore, a two-block full factorial design $2^{6}+2$ center points for each block was created, proposing 68 experiments in a randomized order. This design was applied to a mix standard solution containing $3 \mu \mathrm{g} / \mathrm{mL}$ DCA, $1 \mu \mathrm{g} / \mathrm{mL}$ Diuron and Irgarol 1051 in methanol.

The standardized Pareto charts for the tested compounds are illustrated in Online Resource (Figure S5). The $\mathrm{R}^{2}$ ranged from 93\% for Irgarol 1051 up to $96 \%$ for Diuron, indicating the good fit of the model to the experimental data. From the results, it can be observed that the effect of the APCI parameters tested on the ionization of DCA differ considerably from the effect on the ionization of Diuron and 


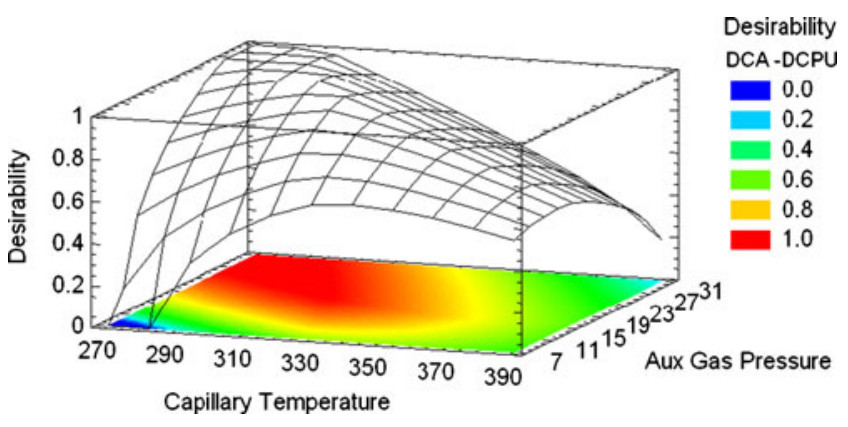

Figure 5. Estimated response surface for desirability of DCA and DCPU peak areas. Y-distance (micrometer position): 0.55 , sheath gas pressure: $60 \mathrm{psi}$

Irgarol 1051. The mobile phase flow rate is the most critical parameter for DCA with a high negative effect, whereas this parameter has a low positive effect for Irgarol 1051 and Diuron. Ion transfer capillary temperature is a critical factor for all the three compounds, but with opposite signs between DCA and the other two. Auxiliary and sheath gas pressures along with the vaporiser temperature are among the critical factors as well, with considerable negative effects (6-14) for Diuron and Irgarol 1051, but with lower positive effect for DCA $(<5)$. The discharge current did not affect the output signal for any of the tested compounds. In the Pareto charts, a number of joint effects can be identified that involve the five aforementioned critical parameters. However, the most frequent and with the highest impact is the interaction between the mobile phase flow rate and the ion transfer capillary temperature (Online Resource, Figure S5, AC effect). From the above observations, it can be assumed that DCA demands more intense conditions for desolvation, as it has been concluded for ESI, as well. On the contrary, Diuron and Irgarol 1051 need milder conditions in terms of gas pressures and temperatures. The selection of the ion transfer capillary temperature and the vaporizer temperature was based on the optimum values of Diuron and Irgarol 1051 because the effect on these compounds was higher than in DCA.

The effect of mobile phase flow rate was further evaluated with multilevel SIM experiments between 0.1 and $0.5 \mathrm{~mL} / \mathrm{min}$ with four replicates per level to a standard mixture of all the target compounds $(1-2 \mu \mathrm{g} / \mathrm{mL})$. Figure 6 presents the SIM peak areas and the corresponding $\mathrm{S} / \mathrm{N}$ ratio versus the mobile phase flow rate. It is observed that $\mathrm{S} / \mathrm{N}$ is more affected than the peak areas. In particular, the increase of the mobile phase flow rate decreases the S/N for DCA, does not influence DCPU and DCPMU, and it increases the values for Diuron, M1, and Irgarol 1051. These data lead to the assumption that flow rate effect is compound dependent in APCI. This speculation can be also based on reported positive [36] and negative [37] flow rate effect on APCI for different compounds with different instrumentation. A flow rate of $0.15 \mathrm{~mL} / \mathrm{min}$ was finally selected, because of the lower sensitivity of DCA at higher flow rates. These results are in accordance with those obtained from the screening experiments for DCA, Diuron, and Irgarol 1051 (Online Resource, Figure S5).
Under the same conditions, multilevel experiments were also conducted for the APCI probe position. Different Ydistances (Figure 1) were tested, varying micrometer position, between values 0.5 and 1.5 that correspond to $\sim 1.4-3.8 \mathrm{~cm}$ from the entrance cone, with six replicates per level to standard solutions of DCA, DCPMU, Diuron, and Irgarol 1051. Again, DCA presented a different behavior compared with the other analytes. The peak area and $\mathrm{S} / \mathrm{N}$ of phenylureas and the triazine decreased as the distance increased. On the contrary, the $\mathrm{S} / \mathrm{N}$ of DCA increased as the distance increased, whereas its peak area was not affected. These data indicate that DCA needs a longer path to desolvate and to be transferred to the gas phase and then become ionized, in contrast to ESI, where the $\mathrm{MH}^{+}$signal of DCA was favored at the closest distance between the needle tip and the entrance cone. This is rational since in ESI the ionization takes place in the liquid phase and the closest the distance is, the less the losses of the spray droplets. The final values of the sheath and auxiliary gas pressure were based on the optimum peak area of DCA that was obtained from multilevel experiments (10-40 arbitrary units for auxiliary gas flow rate that correspond to $\sim 3-12 \mathrm{~L} / \mathrm{min}$ and $20-60 \mathrm{psi}$ for sheath gas). Tube lens and skimmer voltages were optimized as for ESI and the optimum values are defined in the Experimental section and given in Table 1.

\section{Matrix Effect-Signal Suppression}

Comparison of the signal suppression in ESI and APCI was performed by measuring mussel, sediment, and sea water samples in both modes. The signal suppression in ESI was significantly more intense than that occurring in APCI for all the compounds in the three matrices (Online Resource Figure S6). It has been proposed that ionization suppression involves mainly changes in the droplet solution properties caused by the presence of non-volatile solutes in ESI ionization of complex extracts, rather than gas phase reactions leading to the loss of net charge on the analyte that may occur in APCI [38]. Although the results indicate that the ESI method suffers from matrix effect, the signal suppression occurs in the beginning of the chromatogram before the elution of the target compounds and only M1, which is the earlier eluting compound, would be potentially more affected from signal suppression. Next, the effect of the SPE clean-up of sediment and mussel on signal suppression in ESI was investigated. Measurements of purified and non-purified extracts of the environmental samples showed that SPE clean-up reduces to some extent the signal suppression in sediment and mussel, with a little bit sharper negative peaks, but matrix effect is still present even in the purified samples in the same time region for all the compounds (Online Resource Figure S6). It should be noted that this is only a qualitative estimation of the ionization suppression. The aim of these experiments is to locate the time region of the signal suppression and potentially modify the HPLC conditions in order to differ- 
(a)

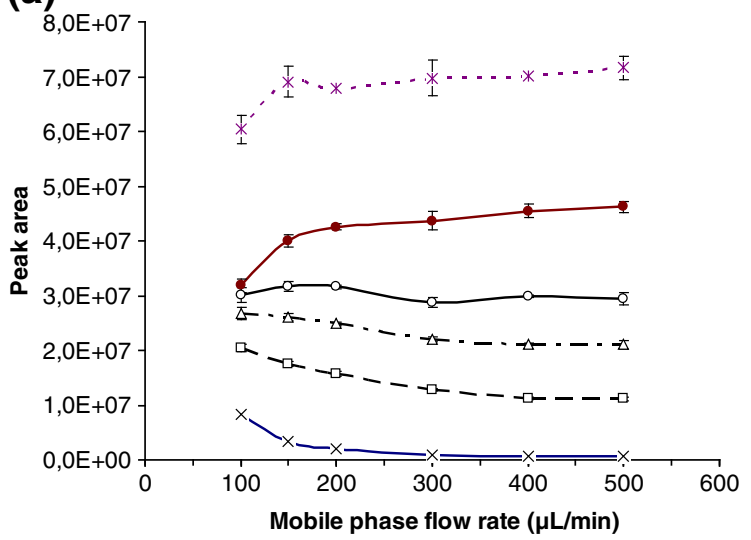

(b)

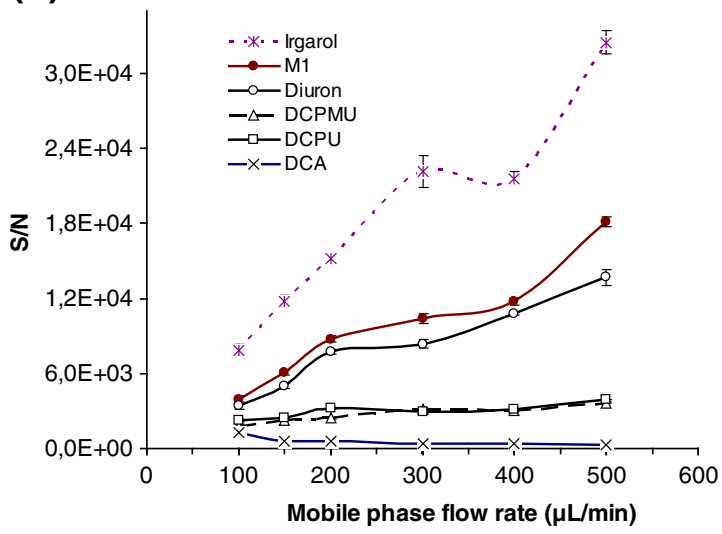

Figure 6. Effect of the mobile phase flow rate on: (a) the peak area and (b) the $\mathrm{S} / \mathrm{N}$ ratio of the analytes measured with $\mathrm{APCl}$

entiate the retention time of matrix components and target compounds and finally minimize the matrix effect on the analytes.

\section{Method Performance}

The instrumental LODs for ESI ranged between $0.02 \mathrm{ng} / \mathrm{mL}$ (Irgarol 1051) and $0.33 \mathrm{ng} / \mathrm{mL}$ (DCPU), and between $0.3 \mathrm{ng} /$ $\mathrm{mL}$ (Irgarol 1051) and $4.9 \mathrm{ng} / \mathrm{mL}$ (DCA) for APCI (all the values are summarized in Online Resource, Table S3). It is noteworthy that the LOD of DCA in APCI is $~ 50$ times higher than the LOD in ESI. The validation data for the non-purified marine sediments, mussels, and sea water and for the sediments with SPE clean-up are summarized in Online Resource (Tables S4, S5, S6 and S7). The LODs ranged between 0.6 and $3.5 \mathrm{ng} / \mathrm{g}$ for sediment and mussel, and between 1.3 and $1.8 \mathrm{ng} / \mathrm{L}$ for sea water. These values are satisfying in terms of environmental monitoring and are comparable to other proposed LC-MS/MS methods [15-18]. The higher LODs for sediments and mussels without clean-up of the proposed methods are due to the absence of any purification step. However, these methods are faster and cheaper. Table 3 summarizes the (\%) SRM ratios of the confirmation transition peak area $(\mathrm{C})$ to the quantitation transition peak area $(\mathrm{Q})$, along with their standard deviation for the different matrices. No remarkable differences are observed among the standard solutions and the environmental matrices.

\section{Application of the Method}

Samples were measured in the framework of a monitoring program for the detection of antifouling biocides in Greek marine environment. The confirmation criteria for the detection of the analytes in the samples comprized of their relative retention time, which should correspond to that of the daily standard solution at a tolerance of $2.5 \%$ [39]. Additionally, the ion ratio confirmation was based on the ion coelution test, according to which the retention time of the qualifier ion should be within $\pm 0.1 \mathrm{~min}$ of the retention time of the "quan" ion, and the ion ratio test, for which the measured ratio $\mathrm{C} / \mathrm{Q}(\%)$ was allowed to vary from the target ratio of the corresponding matrix (Table 3) within the tolerance given by the EU Decision 2002/675, namely $\pm 50 \%$ for Irgarol $1051, \mathrm{M} 1$, and Diuron, $\pm 30 \%$ for DCA, $\pm 25 \%$ for DCPU, and $\pm 20 \%$ for DCPMU. Representative chromatograms of the quantitation (Q) and confirmation (C) SRM transitions of the compounds in marine water, sediment, and mussel extracts are given in Online Resource (Figs. S7, S8, and S9).

\section{Conclusions}

This paper suggests a detailed strategy for the development and optimization of LC-API-MS/MS methods. It is shown that the most critical step is the selection of ionization mode (ESI or APCI), polarity, and mobile phase. There are cases (DCA)

Table 3. \% Ratios of Confirmation (C) to Quantitation (Q) SRM Peak Areas in Standard Solution and Environmental Samples

\begin{tabular}{|c|c|c|c|c|c|}
\hline \multirow[t]{2}{*}{ Compound } & \multicolumn{5}{|c|}{$(\mathrm{C} / \mathrm{Q} \times 100) \pm \mathrm{SD}(n=6)$} \\
\hline & STD* $1-10 \mathrm{ng} / \mathrm{mL}$ & Sea water $1 \mathrm{ng} / \mathrm{mL}$ & Ground water $10 \mathrm{ng} / \mathrm{L}$ & Sediment $10 \mathrm{ng} / \mathrm{g}$ & Mussel $10 \mathrm{ng} / \mathrm{g}$ \\
\hline Irgarol 1051 & $5.7 \pm 0.4$ & $5.60 \pm 0.04$ & $5.8 \pm 0.3$ & $5.3 \pm 0.5$ & $5.7 \pm 0.6$ \\
\hline M1 & $6.5 \pm 0.7$ & $6.6 \pm 0.2$ & $6.6 \pm 0.2$ & $7.0 \pm 0.4$ & $7.5 \pm 0.9$ \\
\hline Diuron & $9.0 \pm 1.5$ & $9.9 \pm 0.3$ & $6.2 \pm 1.4$ & $6.7 \pm 3.0$ & $8.1 \pm 3.0$ \\
\hline DCPMU & $76.0 \pm 6.7$ & $76.2 \pm 1.8$ & $76.3 \pm 7.1$ & $75 \pm 12$ & $74.0 \pm 7.9$ \\
\hline DCPU & $41.1 \pm 6.2$ & $38.4 \pm 0.9$ & $35.6 \pm 6.9$ & $34.4 \pm 8.7$ & $45.6 \pm 7.8$ \\
\hline DCA & $18.0 \pm 0.8$ & $19.2 \pm 0.4$ & $15.8 \pm 2.6$ & $15.9 \pm 3.6$ & $14.8 \pm 3.5$ \\
\hline
\end{tabular}

* $1 \mathrm{ng} / \mathrm{mL}$ for Irgarol 1051 and M1, $10 \mathrm{ng} / \mathrm{mL}$ for Diuron, DCPMU, DCPU, and DCA 
where the organic solvent determines whether the compound is going to be ionized or not, depending on the adaptability of the analyte-solvent cluster. Liquid chromatography should be examined in order to check adequate resolution of analytes. In the present study, it is shown that for the simultaneous determination of Diuron and its degradation products, chromatographic peaks must be well resolved because of (1) source collision induced dissociation of parent compounds to DCA (APCI and ESI) and common product ions, and (2) common $\mathrm{m} / \mathrm{z}$ of DCPU with the solvent adduct of an isotope of DCA (ESI) and common product ion in SRM transitions. Having defined the mobile phase, selection of the ion source critical parameters is accomplished by screening experiments using experimental design. Then, further multilevel experiments are conducted for location of the optimum values of the critical parameters. At this point, it is noteworthy that some compounds (e.g., DCA) need intense drying conditions while others (e.g., DCPU) do not. In such cases, multiple response optimization can be performed in order to achieve maximization of both responses simultaneously combined in one function. Next, the effect of skimmer offset voltage is investigated, especially for the compounds having solvent adducts. Application of skimmer offset voltage was proven necessary in order to eliminate the abundant $\mathrm{ACN}$-adduct ions of DCA and DCPU. Finally, optimization of the SRM data acquisition settings of the software, such as scan time and chromatography filter, using a low concentration standard, can contribute to the improved quality of the acquired data. One essential characteristic of the proposed plan are loops in the optimization strategy. It should be kept in mind that it is possible to return to a previous step and re-optimize the corresponding parameters, especially between the optimization of the ion source parameters and the liquid chromatography optimization.

Comparison of ESI and APCI showed that the best ionization technique for all the target compounds (triazines, phenylureas, and dichloroaniline) was ESI $(+)$. The followed experimental design showed that the effect of ESI and APCI parameters is compound-dependent. It is noteworthy that the effect of the mobile phase flow rate was also compounddependent in APCI. Matrix effect experiments showed that signal suppression in ESI is significantly more intense than that occurring in APCI in mussel, sediment, and sea water matrices. SPE clean-up reduced to some extent the signal suppression in both matrices (sediment and mussel), but matrix effects were still present even in the purified samples in the same time region.

The aforementioned optimization resulted in sensitive and reliable LC-ESI-MS/MS methods suitable for environmental monitoring of Irgarol 1051, Diuron, and their degradation products.

\section{Acknowledgments}

N.C.M. gratefully acknowledges the Greek State Scholarships Foundation for financial support. The authors acknowledge the Greek General Secretariat for Research and Technology for financial support.

\section{References}

1. Konstantinou, I.K., Albanis, T.A.: Worldwide occurrence and effects of antifouling paint biocides in the aquatic environment: a review. Environ. Int. 30, 235-248 (2004)

2. Liu, D., Maguire, R.J., Lau, Y.L., Pacepavicius, G.J., Okamura, H., Aoyama, I.: Transformation of the new antifouling compound Irgarol 1051 by Phanerochaete chrysosporium. Water Res. 31, 2363-2369 (1997)

3. Liu, D., Pacepavicius, G.J., Maguire, R.J., Lau, Y.L., Okamura, H., Aoyama, I.: Mercuric chloride-catalyzed hydrolysis of the new antifouling compound Irgarol 1051. Water Res. 33, 155-163 (1999)

4. Okamura, H., Aoyama, I., Liu, D., Maguire, R.J., Pacepavicius, G.J., Lau, Y.L.: Photodegradation of Irgarol 1051 in water. J. Environ. Sci. Health B 34(2), 225-238 (1999)

5. Giacomazzi, S., Cochet, N.: Environmental impact of Diuron transformation: a review. Chemosphere 56, 1021-1032 (2004)

6. Gatidou, G., Thomaidis, N.S.: Evaluation of single and joint toxic effects of two antifouling biocides, their main metabolites and copper using phytoplankton bioassays. Aquat. Toxicol. 85, 184-191 (2007)

7. Lintelmann, J., Katayama, A., Kurihara, N., Shore, L., Wenzel, A.: Endocrine disruptors in the environment. Pure Appl. Chem. 75(5), 631681 (2003)

8. Sanderson, T., van de Berg, M.: Interactions of xenobiotics with the steroid hormone biosynthesis pathway. Pure Appl. Chem. 75(11-12), 1957-1971 (2003)

9. The list of lists, Pesticide Action Network UK (2005) (http://pan-uk.org/) (Accessed December 2010)

10. Takeuchi, S., Iida, M., Yabushita, H., Matsuda, T., Kojima, H.: In vitro screening for aryl hydrocarbon receptor agonistic activity in 200 pesticides using a highly sensitive reporter cell line, DR-EcoScreen cells, and in vivo mouse liver cytochrome P450-1A induction by Propanil, Diuron and Linuron. Chemosphere 74, 155-165 (2008)

11. Bauer, E.R.S., Meyer, H.H.D., Stahlschmidt-Allner, P., Sauerwein, H.: Application of an androgen receptor assay for the characterization of the androgenic or antiandrogenic activity of various phenylurea herbicides and their derivatives. Analyst 123, 2485-2487 (1998)

12. Kobayashi, N., Okamura, H.: Effects of new antifouling compounds on the development of sea urchin. Mar. Pollut. Bull. 44, 748-751 (2002)

13. Gatidou, G., Kotrikla, A., Thomaidis, N.S., Lekkas, T.D.: Determination of two antifouling booster biocides and their metabolites in marine sediments by high performance liquid chromatography-diode array detector. Anal. Chim. Acta 505, 153-159 (2004)

14. Gatidou, G., Kotrikla, A., Thomaidis, N.S., Lekkas, T.D.: Determination of the antifouling booster biocides Irgarol 1051 and Diuron and their metabolites in seawater by high performance liquid chromatography-diode array detector. Anal. Chim. Acta 528, 89-99 (2005)

15. Harino, H., Midorikawa, S., Arai, T., Ohji, M., Duc Cu, N., Miyazaki, N.: Concentrations of booster biocides in sediment and clams from Vietnam. J. Mar. Biol. Assoc. U. K. 86, 1163-1170 (2006)

16. Sapozhnikova, Y., Wirth, E., Schiff, K., Brown, J., Fulton, M.: Antifouling pesticides in the coastal waters of Southern California. Mar. Pollut. Bull. 54, 1962-1989 (2007)

17. Ghanem, A., Bados, P., Perreau, F., Benabdallah, R., Plagellat, C., Alencastro, L.F., Einhorn, J.: Multiresidue analysis of Atrazine, Diuron and their degradation products in sewage sludge by liquid chromatography tandem mass spectrometry. Anal. Bioanal. Chem. 391, 345-352 (2008)

18. Marín, J.M., Sancho, J.V., Pozo, O.J., López, F.J., Hernández, F.: Quantification and confirmation of anionic, cationic and neutral pesticides and transformation products in water by on-line solid phase extraction-liquid chromatography-tandem mass spectrometry. J. Chromatogr. A 1133, 204-214 (2006)

19. Di Corcia, A., Constantino, A., Crescenzi, C., Samperi, R.: Quantification of phenylurea herbicides and their free and humic acid-associated metabolites in natural waters. J. Chromatogr. A 852, 465-474 (1999)

20. Lindh, C.H., Littorin, M., Amilon, Å., Jönsson, B.A.G.: Analysis of 3,5-dichloroaniline as a biomarker of vinclozolin and iprodione in 
human urine using liquid chromatography/triple quadrupole mass spectrometry. Rapid Commun. Mass Spectrom. 21, 536-542 (2007)

21. Will, W.: Determination of vinclozolin metabolites in human urine by high-performance liquid chromatography and electrochemical detection. Fresenius J. Anal. Chem. 353, 215-218 (1995)

22. Turci, R., Barisano, A., Balducci, C., Colosio, C., Minoia, C.: Determination of dichloroaniline in human urine by gas chromatography/mass spectrometry: validation protocol and establishment of Reference Values in a population group living in central Italy. Rapid Commun. Mass Spectrom. 20, 2621-2625 (2006)

23. Titato, G.M., Bicudo, R.C., Lanças, F.M.: Optimization of the ESI and APCI experimental variables for the LC/MS determination of striazines, methylcarbamates, organophosphorous, benzimidazoles, carboxamide, and phenylurea compounds in orange samples. J. Mass Spectrom. 42, 1348-1357 (2007)

24. Moberg, M., Bergquist, J., Bylund, D.: A generic stepwise optimization strategy for liquid chromatography electrospray ionization tandem mass spectrometry methods. J. Mass Spectrom. 41, 1334-1345 (2006)

25. Moberg, M., Bylund, D., Danielsson, R., Markides, K.: Optimization strategy for liquid chromatography-electrospray ionization mass spectrometry methods. Analyst 125, 1970-1976 (2000)

26. Seto, C., Bateman, K.P.: Development of generic liquid chromatography-mass spectrometry methods using experimental design. J. Am. Soc. Mass Spectrom. 13, 2-9 (2002)

27. Riter, L.S., Vitek, O., Gooding, K.M., Hodge, B.D., Julian, R.K.: Statistical design of experiments as a tool in mass spectrometry. J. Mass Spectrom. 40, 565-579 (2005)

28. Panagiotoglou, E.K., Gatidou, G., Thomaidis, N.S.: Simultaneous determination of two antifouling booster biocides and their degradation products in mussel tissue by HPLC-DAD. 5th International Conference on Instrumental Methods of Analysis Modern Trends and Applications (IMA 2007), September 30-October 4, Patras, Greece, p.121 (2007)
29. Thomson, B.A., Iribarne, J.V.: Field induced ion evaporation from liquid surfaces at atmospheric pressure. J. Chem. Phys. 71, 4451-4463 (1979)

30. http://chem.sis.nlm.nih.gov/chemidplus/chemidlite.jsp (Accessed December 2010)

31. Watson, J.T., Sparkman, O.D.: Introduction to mass spectrometry, 4th edn, p. 669. John Wiley and Sons, Sussex (2007)

32. Bruins, A.P.: Mass spectrometry with ion sources operating at atmospheric pressure. Mass Spectrom. Rev. 10, 53-77 (1991)

33. Thurman, E.M., Ferrer, I., Barcelo, D.: Choosing between atmospheric pressure chemical ionization and electrospray ionization interfaces for the HPLC/MS analysis of pesticides. Anal. Chem. 73, 5441-5449 (2001)

34. Bourcier, S., Hoppiliard, Y., Kargar, T.: Use of plasma desorption mass spectrometry for pesticides analysis: the s-alkylaminotriazines. Rapid Commun. Mass Spectrom. 9, 1213-1223 (1995)

35. Maragou, N.C., Rosenberg, E., Thomaidis, N.S., Koupparis, M.A.: Direct determination of the estrogenic compounds 8-prenylnaringenin, zearalenone, $\alpha$ - and $\beta$-zearalenol in beer by liquid chromatography-mass spectrometry. J. Chromatogr. A 1202, 47-57 (2008)

36. Gallagher, R.T., Balogh, M.P., Davey, P., Jackson, M.R., Sinclair, I., Southern, L.J.: Combined electrospray ionization-atmospheric pressure chemical ionization source for use in high-throughput LC-MS applications. Anal. Chem. 75, 973-977 (2003)

37. Garcia, D.M., Huang, S.K., Stansburry, W.F.: Optimization of the atmospheric pressure chemical ionization liquid chromatography mass spectrometry interface. J. Am. Soc. Mass Spectrom. 7, 59-65 (1996)

38. King, R., Bonfiglio, R., Fernandez-Metzler, C., Miller-Stein, C. Olah, T.: Mechanistic investigation of ionization suppression in electrospray ionization. J. Am. Soc. Mass Spectrom. 11, 942-950 (2000)

39. EEC. COMMISSION DECISION 2002/657, of 12 August 2002 implementing Council Directive 96/23/EC concerning the performance of analytical methods and the interpretation of results $(2002 / 657 / \mathrm{EC})$. Off. J. Eur. Commun. L221:8-36 